\title{
Biography Tadanori Tomita: ISPN President 2011-2012
}

\author{
Tadanori Tomita
}

Received: 6 May 2013 / Accepted: 8 May 2013

(C) The Author(s) 2013. This article is published with open access at Springerlink.com

\section{Dear Editor:}

My father, Tadao, was from Himeji, Japan, and a graduate of Tokyo Veterinary School of Nihon University. Both my paternal grandfather and great grandfather were high-ranking military officers in the Japanese Imperial Army. My father was a cavalry officer stationed in Manchuria under Japanese control when he met my mother. My mother, Noriko, was from Niigata of Northern Japan, and her father worked for the National Rail Service. She was working as a clerk at her uncle's store in Manchuria, where she met my father and they married. Under extreme stress and with a lot of stories to tell, my parents fled from Manchuria to Japan mainland shortly after World War II. Upon returning, they settled in Ikeda City, a beautiful northern suburb of Osaka at the base of Satsuki Mountain. In spite of its location, only 20 min by train from downtown Osaka, Ikeda was a rural community, and the majority of the lands were rice fields. I was born in November of 1945 and was their first born child. My sister was born 5 years later and together we were raised in a humble yet comfortable house (Fig. 1). We enjoyed cherry and azalea blossoms in the spring and went to the Inagawa River to catch fish and enjoyed firework in the summer. Autumn, we went to the mountain to pick chestnuts and persimmons, and enjoyed the change of the leaves. My father opened a busy veterinary clinic in Ikeda City which he loved and worked at until his death at the age of 74 . It was observing his gentle and diligent care of the animals that first fostered my interest in medicine.

\section{T. Tomita $(\bowtie)$}

Division of Pediatric Neurosurgery, Ann \& Robert H. Lurie

Children's Hospital of Chicago, 225 E. Chicago Avenue,

Chicago, IL 60611-2605, USA

e-mail: ttomita@luriechildrens.org

\section{Undergraduate education}

Both my sister and I attended National Osaka Teacher's University Lab School for elementary and junior high school (Fig. 2). Then, I went to Kitano High School in Osaka. I played basketball, and our team went to the state final but lost the championship game. In 1964, I passed an entrance exam and was accepted to Kobe University. The Tsurukabuto Campus where I spent my premed education is located in the side of Mount Rokko overlooking the beautiful port city of Kobe. The night view from the mountain is compared to "a million dollar's scene." My sister, Yuriko, also showed an interest in medicine, and followed me to Kobe. Japanese medical education is comprises of 2 years of premed courses at a liberal arts college followed by 4 years of medical school. My premed curriculum was very demanding, and according to the administrator, "the hardest in the world."

One day during the second year of my premed experience, I was summoned to the office of Professor Takeda of the First Department of Anatomy of the medical school. I went with fear in my mind because I was a mere premed student, about to encounter a professor of notoriety for his quick temper and bizarre behavior. Contrary to my expectation, he greeted me with a smile. Frank Netter's, Nervous System Book, was set in front of me. Professor Takeda said that all incoming medical students had to acquire the book for his brain anatomy class. Handing me a copy of the book, he asked me to get a purchase order from each medical student for the book. On the train ride back to the Tsurukabuto Campus, I started to read this beautiful book, and found myself totally lost in the world of "brain anatomy." That was my first encounter with the human brain and to this date I have no idea why Professor Takeda chose me.

In spite of the hard curriculum, I managed to play rugby, throughout my college and medical school life (Fig. 3). My position was number 6 . Rugby practice took place every day 


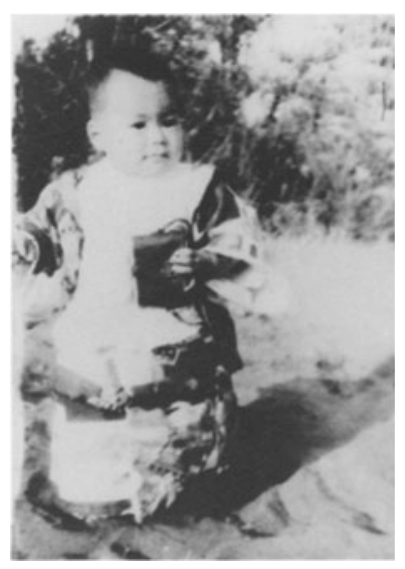

Fig. 1 An infant picture of Tadanori Tomita

except for Monday with games on Sunday. It was a big part of my life during those years teaching me discipline and teamwork. I still remember the intense two-a-day practices during spring and summer camp. Tragically, at one of the games when I was 20 , I collided with my teammate head-on during a tackle chasing after an opponent. Both of us sustained a concussion, and my teammate was sidelined and started to vomit, but I continued to play. Replacement of a player was not allowed in those days, no matter what. That evening my teammate underwent a craniotomy for decompression of his fractured optic canal because he lost sight in his right eye, which he never regained. This experience, which is still very painful to think of, guided me further toward neurosurgery.

\section{Postgraduate training in Japan}

After graduation from medical school, I was accepted as a rotating intern majoring in neurosurgery at St. Luke's International Hospital. I was very fortunate to have daily

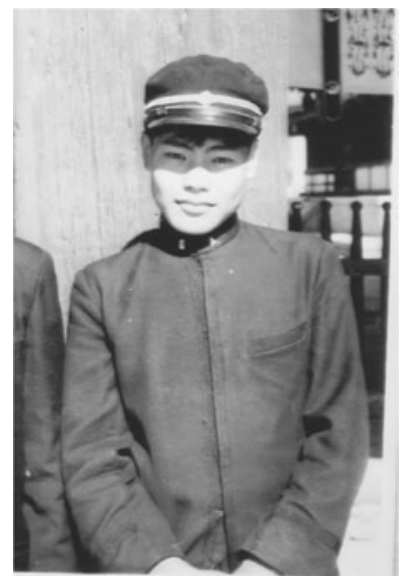

Fig. 2 Tadanori Tomita's at eighth grade picture

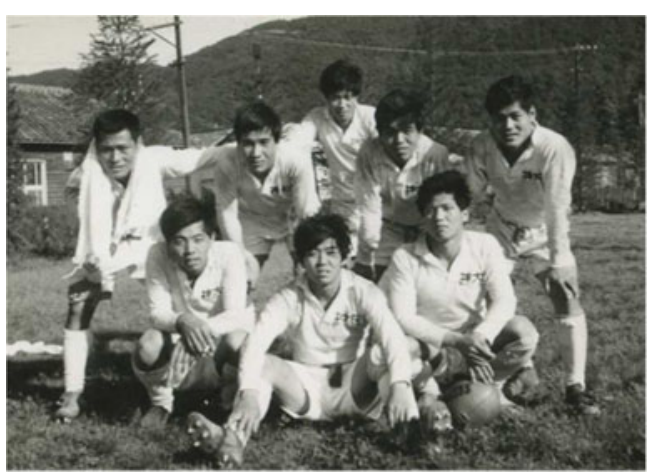

Fig. 3 A picture of the forwards on Tomita's Kobe University rugby team

exposure to Dr. Iwashita a neurosurgeon, Dr. Nishimura a pediatrician, and Dr. Honda a neurologist, all who were trained in the USA. There I began to have an interest in pediatric neurosurgery. In the middle of the second year, I learned that Kobe University had established a Department of Neurosurgery and Professor Satoshi Matsumoto was invited to be the first chairman. I had no hesitation to return to Kobe to receive my neurosurgery residency under him. Fortunately, I passed my Ph.D. entrance exam, was accepted and thus returned to Kobe in April 1972.

In addition to the neurosurgery training in Kobe, I had the opportunity to participate in research work, studying both human and canine hydrocephalus. Matsumoto was interested in intrathecal saline infusion testing for hydrocephalus, and we found interesting data after performing this in a 100 patients. As a naïve first-year neurosurgery resident, I ended up as one of the discussants presenting our results of the infusion test along with well-recognized professors, at the Symposium on Normal Pressure Hydrocephalus at the annual meeting of Japan Neurosurgery Society in November 1972.

Matsumoto trained in Chicago under Professor Anthony Raimondi. They became fast friends since Matsumoto was the first resident of Raimondi at Cook County Hospital and Children's Memorial Hospital. They were both young and had a common interest in pediatric neurosurgery. In 1972, a preparatory meeting for ISPN was held in Kobe where Drs. Tony Raimondi, Raul Carrea, Byron Pevehouse, and others were attended. That was my first encounter with Professor Raimondi. I picked him up at Osaka Airport and took him to Kobe in my Toyota. In route, I explained to him my research project of the canine model of hydrocephalus. In 1973, the first annual meeting was held in Tokyo, and Matsumoto was the first meeting chairman. The entire crew of the Neurosurgery Department of Kobe University participated in various roles for the meeting; I as one of slide projectionists. That year, Raimondi accepted me as a neurosurgery resident at Northwestern University. The next 
6 months prior to leaving Japan, I tried to brush up on my English. I also read through Raimondi's textbook Pediatric Neuroradiology, and Donald Matson's textbook Neurosurgery of Infancy and Childhood. I was ready for "American Neurosurgery."

\section{Postgraduate training in USA}

The flight was brought me to Chicago from Narita. I arrived at O'Hare airport late on July 4, 1974. I still appreciate Dr. Keiichi Kuwamura, who was 1 year senior to me at Kobe, for greeting me there in the vastly empty airport. I did not know it was a holiday in the USA. I had a lot to learn.

During my 6-year residency at Northwestern, I spent two and a half years in pediatric neurosurgery at Children's Memorial Hospital. My first 6 months were spent in pediatric neurology. It was a terrific rotation because I did not have any experience examining neonates and infants. During that time, one of my neurology patients with a recent seizure history was found to have a metastatic calcified brain lesion. Raimondi was the surgeon and I went to observe the case. That was the first time I stepped in the operating room in the US. Although the OR was small and old, it gave me big thrills to observe by the very famous Professor Tony Raimondi in his operative theater. During that time, there was a conference every Saturday morning. Raimondi, who pioneered pediatric neuroradiology before the CT era, gave a series of lectures and quizzes to each resident about the findings on pneumoencephalogram and angiography. Participants then included Kiyoshi Sato and Ezio Dirocco who were also residents at Children's Memorial Hospital. This conference was unfortunately canceled after 1978 when CT became available and Tom Naidich arrived as a full time neuroradiologist at Children's Memorial Hospital. My first encounter with CT was late in 1975 when I was rotating at Evanston Hospital. A high school girl, who struck her face on a tree branch while riding a horse, developed orbital cellulitis. It was refractory to any antibiotics therapy. Finally, she was evaluated at Northwestern Memorial Hospital that had just acquired CT. Behold, the CT, though very primitive, showed a retained twig in her orbit. She was cured after successful surgery. During my 1-year rotation at Evanston Hospital in 1975, I was attracted to transsphenoidal surgery while working with Dr. Ivan Ciric. Therefore, during that year, using my vacation time, I visited Dr. Julius Hardy, the pioneer of transsphenoidal surgery, in Montreal. In January, Raimondi sent me to New York for 6 months at Memorial Sloan Kettering Cancer Center in New York where Dr. Joseph Galicich, one of the last students of Donald Matson at Boston Children's was the chairman.

I had my first neurosurgery rotation at Children's Memorial in January 1977. There was no CT, and the junior resident's biggest responsibility was to take care of the floor patients and perform angiography. Thanks to Dr. Len Cerullo who brought the technique of femoral catheterization from cardiology lab, I learned the procedure quickly. I actually enjoyed performing angiography and became very good at it. Although pneumo study was less common at that time, but still we did it with the patient in sitting position and injected air through a cisternal puncture. The worst experience at Children's Memorial Hospital, however, was starting IVs in newborn and infants, particularly in the middle of the night. There were no phlebotomists back then.

I had a research year from 1977 to 1978. Raimondi sent me to Dr. Molinaro's Immunology Lab at UIC for 3 months to learn how to extract DNA from tumor tissue in order to isolate viral DNA. After that, Raimondi sent me to Children's Oncology Clinic to learn about chemotherapy for brain tumors, while in its very primitive stage. I read a lot about chemotherapy during that time but could not find any data showing good results on brain tumors; instead, I witnessed a lot of toxicity and failures.

Even during my research year, I had to take every other night on-call for pediatric neurosurgery. One day, Raimondi called Shizuo Oi, Jose Velasco, my fellow residents, and myself to his office, and told us that he was writing chapters for a new pediatric neurosurgery textbook Pediatric Neurosurgery: Surgery of the Developing Nervous System. He wanted us to write a chapter with him, and gave three titles to choose from: "IV Ventricle Tumors," "Ependymomas," and "Choroid Plexus Papilloma." I chose "IV Ventricle Tumor," Shizuo took "Ependymoma," and Jose "Choroid Plexus Papilloma." For me, it was the beginning of my official career in pediatric neurosurgery. I took advantage of my research year by reviewing the patient charts for, not only posterior fossa tumors but other brain tumors as well. The data and collected data became the source of information for my earlier publications.

Because of the lack of senior residents due to a change in the length of residency from 6 to 7 years, my co-resident Ivar Szper and I spent 2 years as chief resident from July 1978 to July 2000. I was chief resident at Children's Memorial Hospital for a year and then chief residents at $\mathrm{NMH}$ and VA for a year. It was the norm at that time that Northwestern residents, regardless of rank, took every other night on-call.

I met Kathryn Bel Morley, who worked as a nurse on the neurosurgery floor, of 2 East at Children's Memorial. She was fresh out from nursing school in 1978. That summer, I 
took her out for Japanese Summer Festival at Midwest Temple in Chicago's Old Town, and we started dating. When Raimondi asked me to stay and join his practice, I had no hesitation to accept his offer primarily because of Kathy. I was supposed to return to Kobe and join Matsumoto's practice in Kobe. However, when Professor Matsumoto came to Chicago for the Congress of Neurological Surgeons in October, 1979, I went to his room at the Whitehall Hotel and told him of my desire to stay in the USA. He was not pleased, but, later gave a nod of approval and congratulated me for my decision.

Professor Raimondi arranged a 1-year general surgery residency at Memorial Sloan Kettering Cancer Center after I finished my neurosurgery residency in order to meet the requirements of the American Board of Neurological Surgery. He wanted me to learn cancer management and bring this knowledge to Northwestern upon my return. Thus a deal was made between Raimondi and Galicich that I would be treated as a Cancer Fellow. I told Kathy about going to New York, and asked her if she would come along. She answered "yes" in the hallway of 2 East where I proposed to her. We got married in Ann Arbor on June 28, 1980, one day after I finished my neurosurgery training. Shizuo Oi was my best man at the wedding. Following the wedding, Kathy and I drove our U-Haul truck to the Big Apple, towing our old yellow Toyota Celica.

Life in Manhattan was very productive. This is where my first son was born in 1981. I had a great rotation at Sloan Kettering where I was treated as a cancer fellow as promised. I rotated through various surgical divisions. During surgeries by Head and Neck, Thoracic Surgery and GI services, it was a great opportunity for me to learn the anatomy of the neck, skull base, and paraspinal structures. At Sloan Kettering, my professors Joe Galicich and Narayan Sundaresan were actively involved in brain and spine cancer management. During that year, I had the opportunities to review, collect date, and later publish a few papers related to the subjects of spinal and brain metastasis, and gliomas. During my rotation in Pediatric Surgery, there were not many brain tumors on the ward but a lot of children with leukemia; therefore, we placed a lot of Ommaya reservoir for intrathecal chemotherapy.

\section{Pediatric neurosurgery practice in Chicago, Illinois}

After Sloan Kettering, we drove back to Chicago now with our new born infant on the last day of June, 1981. We settled in our old apartment building on Orchard Street, one block from Children's Memorial Hospital. I was so excited to be back in Chicago and start my practice in this world renowned place as an attending neurosurgeon. After 1 year, we moved to Glenview, a northern suburb of Chicago where Kathy and I raised our three wonderful boys (Fig. 4).

What a relief, I felt, when I was certified by American Board of Neurological Surgery in 1984. Subsequently, I was certified in 1996 and recertified in 2006 by American Board of Pediatric Neurological Surgery, which was the last test I will have to take. Climbing up the academic ladder, I attained the rank of Professor of Neurological Surgery in 1996. Following a vigorous national search, Children's Memorial Hospital appointed me a Division Head of Pediatric Neurosurgery after Dave McLone relinquished this position in 2001. Also, I have served as a Vice Chair of the Department of Neurosurgery at Northwestern University Feinberg School of Medicine. In 2000, I was invested as the first Yeager Professor of Pediatric Neurosurgery that was established by the family of one of my patients. I have been Director of the Falk Brain Tumor Center, a Director of Pediatric Neurosurgery Fellowship and a Director of Pediatric Neurosurgery Research Program. During this time, I have seen many changes, the greatest being the hospital relocated to downtown of Chicago on June 8, 2012, and subsequent name change to Ann \& Robert H. Lurie Children's Hospital of Chicago (Fig. 5 a-c). The name of Children's Memorial Hospital has been officially retired. The hospital first opened as Maurice F. Porter Memorial Hospital in 1882 and was renamed Children's Memorial Hospital in 1903. It was sad to see the disappearance of the name "Children's Memorial" but life goes on.

During the first month after I started my practice in 1981, I had two cases of very peculiar cerebral hemispheric tumors, both of which turned out to be primary sarcoma. These cases were published later with Dr. Frank Crussi, head of pathology and an authority of sarcoma pathology.

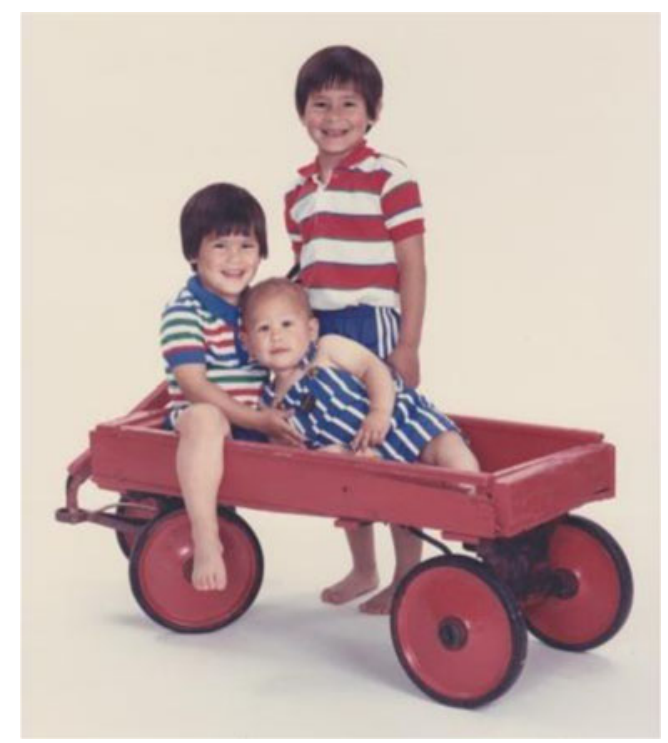

Fig. 4 A picture taken in 1986 of the Tomitas' three sons: Tadaki, Kenji, and Dan 
Fig. 5 Children's Memorial Hospital (a). A picture pointing at the future location of the new hospital through the window of the Children's Memorial Hospital (b). Ann \& Robert H. Lurie Children's Hospital of Chicago (c)

Many fields of the pediatric neurosurgery attracted me, but my interest in pediatric brain tumor was further intensified. After a few years of practice, I recognized the need for a multidisciplinary brain tumor service. Thus, one of my neurosurgery clinics was changed to be the Brain Tumor Clinic in 1986, and soon the hospital administrators accepted and designated it Brain Tumor Center. In 1988, in order to start the weekly Multidisciplinary Pediatric Brain Tumor Board, I invited Pediatric Oncology, Radiation Oncology, Neuroradiology, Neuropsychology, and Neuropathology to join Neurosurgery. This board has been held incessantly since, although the members have changed and increased in number since that time. In 1997, we received a significant philanthropic support from Falk Foundation to established Falk Brain Tumor Research Program. The Falk Brain Tumor Center, comprised of the Clinic, Board and Research Center at Children's Memorial Hospital, was thus established, and I am honored and proud to be the founding director of this Center. The addition of Dr. Stewart Goldman as head of neurooncology really helped to further establish the national recognition of this Center. Hence, we became one of the institutions of Pediatric Brain Tumor Consortium. Also, Stew Goldman and I co-chaired the International Symposium for Pediatric Neurooncology in 2008 in Chicago.

I belong to multiple professional societies: AANS, CNS, ACS, AAP, COG, SNO, etc. In my office, there are two plaques that I value the most: ASPN and ISPN. I remember when the first ASPN meeting was held in January 1978, when I was a senior resident at Children's Memorial. All attendings, Raimondi, Francisco Gutierrez, and McLone were at the meeting on Peter Island in Caribbean. Due to a record breaking snow fall in Chicago, their return was delayed by several days. I was in charge of the service during those days, with cold sweat but no disasters. During the fledgling years of the ASPN, its membership was very strict. I was first invited in 1986 and brought our three sons, the youngest one only 1 year old and second time in 1989, again with children. I became a member of ASPN in 1990. ASPN was an enjoyable place to learn from and associate with senior members such as Fred Epstein and Harold Hoffman. ASPN was the driving force for establishment of the American Board of Pediatric Neurological Surgery in 1996. My associate Dave McLone championed for its establishment and I had the opportunity to watch its development closely. I served on ASPN executive council and also on education committee in the past.

ISPN has been by far more special to me due to the international component and personal involvement. I have
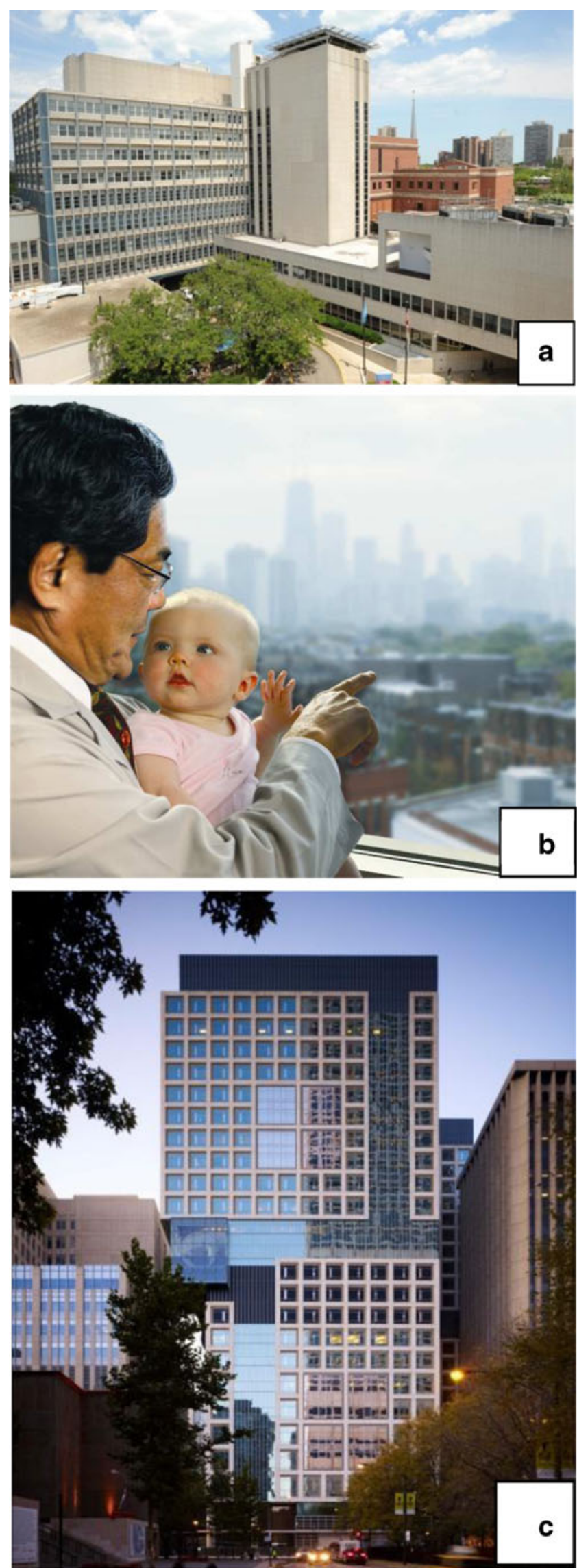
witnessed its progress since the first annual meeting in Tokyo. During my training, I sporadically attended annual meetings, but over the past 25 years I have never missed one. Serving on the executive committee for nearly 10 years has strengthened my attachment to the ISPN. The ISPN gave me the opportunity of acquaintance with many prominent international neurosurgeons with whom I have maintained lifelong friendship. Among the activities in ISPN, the educational courses have been the highlight, because of the opportunity to get acquainted with new friends and different cultures. I have attended 25 ISPN educational courses worldwide since 2000 and particularly appreciate the opportunity serving as ISPN Chairman of Education Committee for 4 years. ISPN has offered me the chances to visit all corners of the world, for which I am extremely grateful. I had the honor of serving as President in 2012 at the 40th Annual meeting in Sydney. Besides ISPN, I am also very grateful to be invited to multiple national and international societies as a guest in 30 occasions and as a visiting professor 18 times. These experiences really enriched my world view. In return, I have been privileged to share my experience with others and hopefully enhance the care of children with neurosurgical disorders.

A Pediatric Neurosurgery Fellowship program for North American residency graduates was started in 1985 at Children's Memorial Hospital and we have had a steady flow of fellows every year since. This program has been supported by American Council for Pediatric Neurosurgery Fellowship, through which the candidates are matched. It has been a privilege to mentor these fellows with my associates, and I am very proud to claim all our graduates took an academic pediatric position at either university hospital or reputable children's hospital in the USA. It is quite fulfilling to see these young men and women graduating every June to their own academic destination to take care of sick children. I have been fortunate to be associated with numerous neurosurgery residents who came through our program to learn pediatric neurosurgery. They are primarily from Northwestern but we also have had regular rotations from Temple, UIC, Rush, Loyola and Brommen over the past 10 years. Thus we routinely have three or four residents at a time on our service, and hold regular teaching conference three times a week. Also, in 2002, we established an International Fellowship program of 1 to 2 years in duration for pediatric neurosurgery. We accept neurosurgeons who completed their training at foreign program and intend to serve as a pediatric neurosurgeon upon return to their country. It is a thrill to see their progress and also it reaffirms the need for postgraduate education and training of pediatric neurosurgery internationally. Besides these clinical programs, I have accepted 18 international neurosurgeons as an International Research Fellow over the years, who conducted research. I am very happy for and proud of these international neurosurgeons with various background who left with very significant published discoveries in neuroscience based on clinical, translational and/or basic scientific investigations.

I continue to value scientific publications which have become readily accessible through the internet. Publications still remain the vehicle for the advancement of science and clinical improvement in medicine. I have served on the editorial board of ten scientific journals, and have been an associate editor of Child's Nervous System for 25 years. More recently, I was appointed to be editor-in-chief of Neuroscience Discovery. Knowing the importance of publishing the scientific discoveries, I have made an effort to publish articles based on either clinical or laboratory investigations. Up to date, I have published 185 articles in refereed journals, of which 115 (62\%) were related to CNS tumors. Also, I was invited to write 38 book chapters covering the subjects of brain tumors as well as hydrocephalus, head trauma, neural tube defects, tethered cord, vascular malformations, and medical education.

\section{Future}

Influenced by my mentors and other great predecessors in my profession, I have emphasized the importance of academic medicine in my work which consists of three elements: clinical service of excellence, education, and research. It is here that I have felt the greatest reward for my academic accomplishment, largely owing to the encouragement from my mentors, the support from my associates, but most importantly from the parents and family who entrusted me with the care of their most precious children. Unfortunately, however, accomplishing all these elements by most of us is getting harder and harder because of the RVU-based compensation formula for surgeons, and the rapid biomedical advancements that make it hard for busy clinicians to catch up. However, it is imperative that one should make an effort to contribute their knowledge and experience to the advancement of our science. Exploring innovative diagnostic and therapeutic methods which can only be initiated by clinicians should communicate to research scientists for cooperative work and joint venture. Sooner or later, subspecialization within pediatric neurosurgery like epilepsy surgery, pediatric spine, neuroendoscopy, functional neurosurgery, etc. may take place along with technological advancements and sophistication and the requirement of a deeper knowledge of these disorders. It is to our young patients we owe this effort.

Open Access This article is distributed under the terms of the Creative Commons Attribution License which permits any use, distribution, and reproduction in any medium, provided the original author(s) and the source are credited. 